\title{
Ultrasound Diagnosis of Exomphalos (Omphalocele): Differentiating Exomphalos from Normal Physiologic Gut Herniation and Gastroschisis
}

\author{
Jitendra Parmar ${ }^{1 *}$, Paresh Shah ${ }^{1}$, Prashant Acharya ${ }^{2}$, Tapan Patel ${ }^{1}$, Sandip Shah ${ }^{1}$, Bhoomi Angirish ${ }^{1}$ and Nishith \\ Chaudhari ${ }^{1}$
}

${ }^{1}$ Department of radiology, Apollo Hospitals International Limited, India

${ }^{2}$ Paras Advanced Center for Fetal Medicine, India

Submission: May 10, 2018; Published: July 02, 2018

*Corresponding author: Jitendra Parmar, Consultant, Department of Radiology, Apollo Hospitals International Limited, Gandhinagar, India, Tel: +919643158267; Email: jitendra32@gmail.com

Abstract

An Exomphalos, also known as omphalocele is a congenital midline abdominal wall defect at the base of the umbilical cord insertion with herniation of gut and/or liver or occasionally other content, out of the fetal abdomen. Many chomosomal anomalies are often associated with this embryologic defect. We present a case report describing ultrasound diagnosis of exomphalos associated with hypoplastic nasal bone and increased nuchal translucency thickness.

Keywords: Ultrasound diagnosis; Exomphalos; Omphalocele; Gut herniation; Gastroschisis; Congenital midline; Embryologic defect; Nuchal translucency; chromosomal anomalies; Gastroschisis; Transvaginal; Ductus venosus; Translucent sac; Wharton jelly; Umbilical vessels; Ovaries; Fetal chromosomal; Cleft palate; Dental malocclusion; Mortality rate; Sinologist; Echogenicity

\section{Introduction}

An Exomphalos, also known as omphalocele is a congenital midline abdominal wall defect at the base of umbilical cord insertion with herniation of gut and/or liver or occasionally other contents, out of the fetal abdomen. Many chromosomal anomalies are often associated with this embryologic defect [1-6]. A gastroschisis is a ventral abdominal wall defect, almost always to the right of the umbilicus from which it is separated by thin skin bridge, and contains abdominal viscera, most commonly small bowels, stomach and gonads without coverings $[7,8]$. During first trimester sonogram, normal physiologic herniation of the fetal bowel seen oftenly between 8 and 12 weeks gestational [9]. With careful detail scanning, the sonographer may be able to differentiate normal physiologic gut herniation from early identification of exomphalos and gastroschisis $[9,10]$. This case report describes a ultrasound diagnosis of exomphalos associated with hypoplastic nasal bone and increased nuchal translucency and discusses how to differentiate exomphalos from normal physiologic gut herniation and gastroschisis.

\section{Case Report}

A 27-year-old woman having her first pregnancy, at the 12 weeks +4 days was referred to the ultrasound (US) department for a routine US without any pertinent past medical history. Transabdominal US, followed by transvaginal US was performed using a 2D (two dimensional) and 3D (three dimensional) ultrasound equipment (Voluson E 10 BT 17; Probe 3.5 MhZ). 2D US showed a single live intrauterine pregnancy with gestational age of 12 weeks +4 days. A well defined rounded solid homogenous mass lesion, measuring $~ 16 \times 15 \mathrm{~mm}$ seen at the umbilical cord insertion site (Figure 1). By using Doppler US and 3D US, an exomphalos containing the liver was identified (Figure 2). US also showed increased nuchal translucency, $3.9 \mathrm{~mm}$ and a hypoplastic nasal bone (Figure 3). Ductus Venosus shows increased PI (3.06) with reversal of 'a' wave (Figure 4). Detailed US for possible associated malformations could not find any other structural defects. The detail ultrasound parameters are 


\section{Global Journal of Reproductive Medicine}

described in Table 1. As a result of the sonographic findings the patient terminated the pregnancy, and no follow-up was able to be obtained. It is unknown whether the patient had the products of conception tested for aneuploidy.

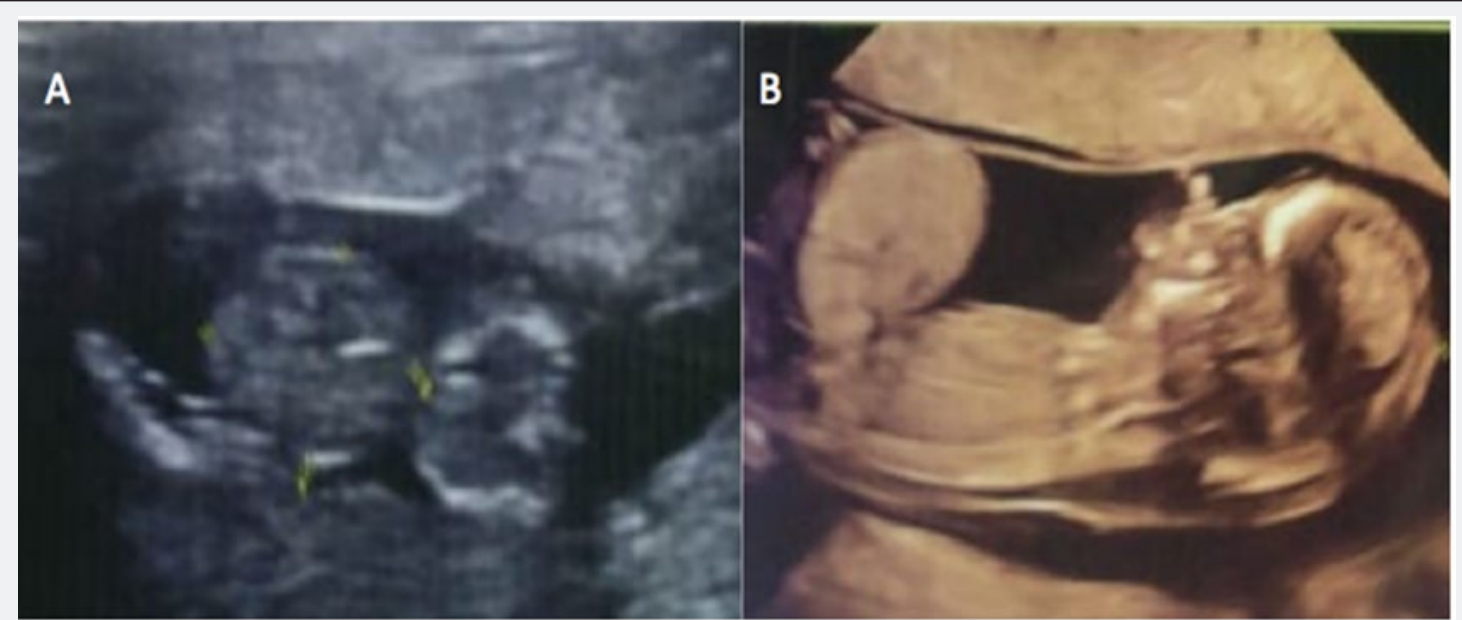

Figure 1: Transabdominal (A) and transvaginal (B) ultrasound showed a well defined rounded solid homogenous mass lesion measuring 16 $x 15 \mathrm{~mm}$ along the anterior abdominal wall at the level of umbilical cord insertion.

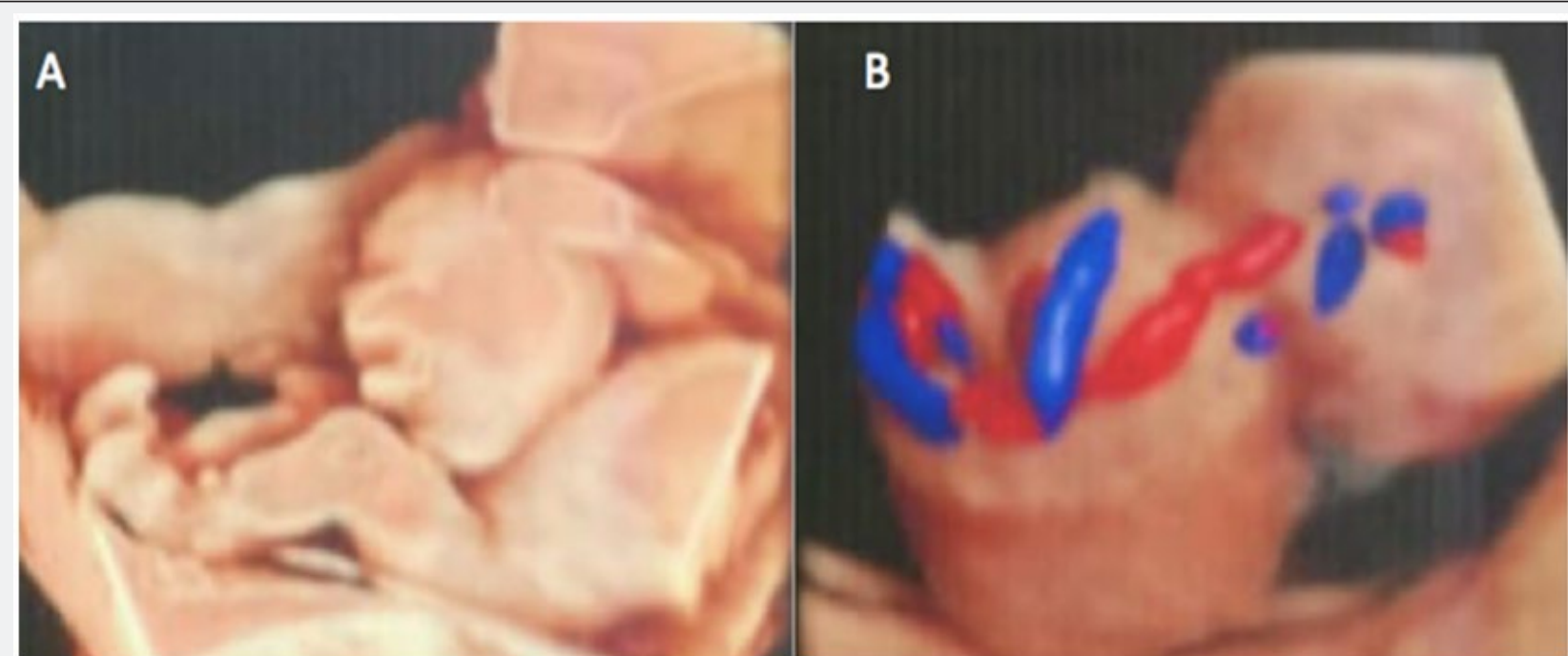

Figure 2: 3D (A) and Doppler ultrasound $(B)$ confirmed exomphalos with the liver as herniated content.

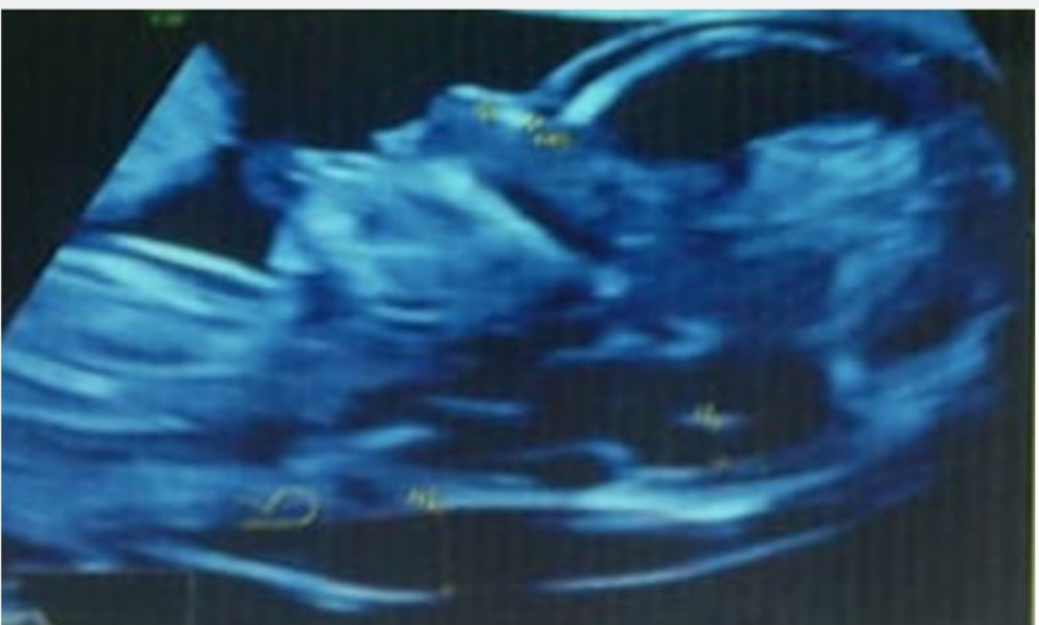

Figure 3: Transvaginal sonography showed increased nuchal translucency $(3.9 \mathrm{~mm})$ and hypoplastic nasal bone. 


\section{Global Journal of Reproductive Medicine}

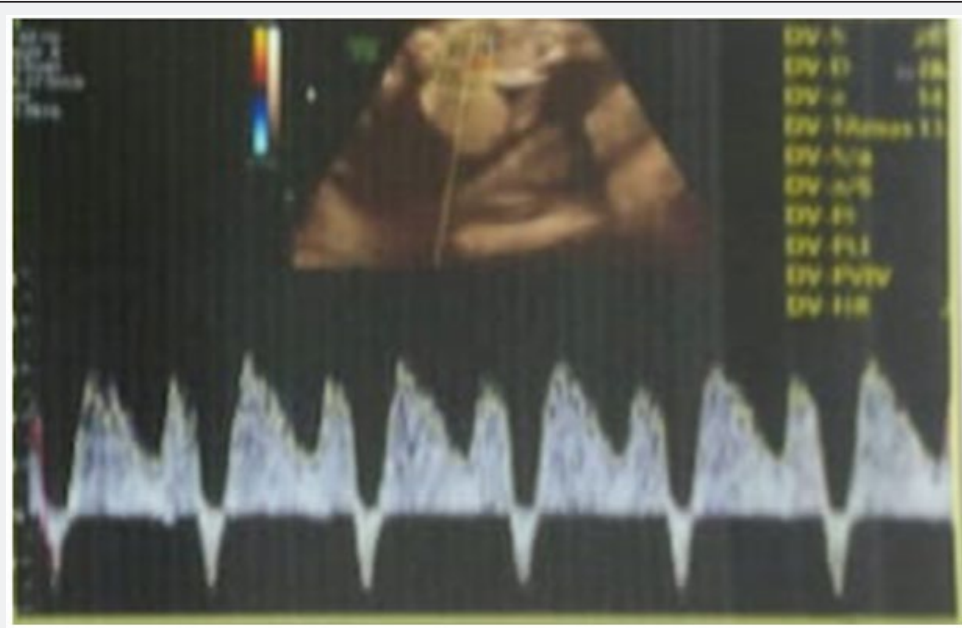

Figure 4: Doppler ultrasound revealed High PI (3.06) of Ductus Venosus with inversion of 'a' wave.

Table 1:

\begin{tabular}{|c|c|}
\hline \multicolumn{2}{|c|}{ Findings } \\
\hline Fetal Heart Rate & $167 \mathrm{BPM}$ \\
\hline Crown-Rump Length & $59.5 \mathrm{~mm}$ \\
\hline Nuchal Translucency & $3.90 \mathrm{~mm}$ \\
\hline Biparietal Diameter & $18.2 \mathrm{~mm}$ \\
\hline Head Circumference & $67.0 \mathrm{~mm}$ \\
\hline Ductus Venosus PI & 3.06 \\
\hline Placenta & Anterior high \\
\hline Amniotic fluid & Adequate \\
\hline Cord & 3 vessels \\
\hline
\end{tabular}

BPM: Beats Per Minute

$\mathrm{Mm}$ : Millimetre

PI: Pulsatility Index

\section{Discussion}

An exomphalos is an encapsulated ventral wall defect containing liver and/or bowel and occurs because of incomplete rotation of bowel returning into the abdominal cavity. The translucent sac, which is composed of the Wharton jelly, amnion and the peritoneum, contains the abdominal viscera with well visualization of the radiation of the umbilical vessels onto the sac wall. In $\sim 50 \%$ of the cases, the herniated bowel accompanied with the liver, spleen, ovaries or the testes $[7,8]$. According to contents of herniation, exomphalos may be categorized as those containing both liver and bowel (extracorporeal liver) and those containing only bowel (intracorporeal liver). Intracorporeal exomphalos can only be reliably diagnosed after 12 weeks, because of the difficulty in distinguishing it from physiologic midgut herniation [11,12]; Such exomphalos have a high rate of foetal chomosomal abnormalities [13,14]. Extracorporeal exomphalos can be diagnosed as early as 9 to 10 weeks, and these may also be associated with fetal chromosomal abnormalities and other birth defects [15-17].
Exomphalos frequently have been associated with other conditions, such as congenital heart disease, cleft palate, musculoskeletal abnormalities, intrauterine growth restriction and dental malocclusion. The incidence of associated chromosomal abnormalities is $10-40 \%$ that include trisomies 12 , $13,15,18$, and 21.3 [18-22]. A featus found to have an exomphalos has a high mortality rate because of its coexistance with multiple anomalies [9,23]. However, because of improvement in the parenteral nutritional, surgical and the anesthetic management techniques, the survival of the exomphalos cases has increased from $60 \%$ during the 1960 s to more than $90 \%$ at present $[7,24]$.

The diagnosis of exomphalos can be made by ultrasound in 1st trimester; however, two close differentials; gastroschisis and physiologic midgut herniation, need to be excluded by careful and detail imaging. One of the most important and specific finding to differentiate exomphalos from midgut herniation is the visualization of herniated liver associated with gut loop within the herniated sac. Few other significant secondary features that differentiate physiologic midgut herniation from exomphalos: by 12 weeks gestational age, midgut herniation descends back into the abdominal cavity; exomphalos have homogenous appearance, while midgut herniation tends to have heterogenous appearance; exomphalos presents as a large circular shaped lesion measuring more than $7 \mathrm{~mm}$, while midgut herniation presents as a small spherical shaped lesion measuring $\sim 4$ to $7 \mathrm{~mm}$. Gastroschisis occurs later because the anterior abdominal wall defect before $16^{\text {th }}$ week is very small and anterior abdominal wall muscles and peristaltic waves are visible only in $14^{\text {th }}$ week. Intestinal convolutions pass through a small defect $(<1 \mathrm{~cm})$, which is localized to the right of the normal umbilical cord insertion and float freely in the amniotic fluid with no membrane covering the content [25].

In cases with difficulty to identify the exact pathology and to demonstrate the co-existing pathologies, the 3D USG may be helpful. Besides its help as a diagnostic tool, the 3D ultrasound may help the family to understand and realize the situation. 


\section{Global Journal of Reproductive Medicine}

The decision process, genetic counselling, perception of the situation and its importance, future planning and the state of the management will be affected by the thorough comprehension and concern of the family. First trimester scanning of the anterior abdominal wall is crucial and at most important. It is important to determine the gestational age of the featus being examined. The sinologist must examine the echogenicity of the herniation at the base of the umbilicus and make a determination as to heterogeneity or homogeneity and whether covering present or absent. Measurements must be taken at the base of the umbilical herniation, if the herniation is too large to be considered a physiologic midgut herniation. As the exomphalos is not usually an isolated finding, a survey must be used to further identified other potential abnormalities.

\section{References}

1. Sanders RC, Blackmon LR, Omphalocele (2002) In: Sanders RC (Eds), Structural Foetal Abnormalities: The Total Picture, $\left(2^{\text {nd }} e d n\right)$, St. Louis, Mosby, USA, Pp 221-223.

2. Graham JM (2010) How do genes affect the risk of having a child with a birth defect? In: Alwan S, Bleyl SB, et al. (Eds), Teratology Primer- $\left(2^{\text {nd }}\right.$ edn), Jefferson Digital Commons, USA, Pp 17-19.

3. Sepulveda W, Wong AW, Fauchon DE (2010) Fetal spinal anomalies in first-trimester sonographic screening program for aneuploidy. Prenat Diagn 31(1): 107-114.

4. Stoll C, Alembik Y,DottB, Roth MP (2008) Omphalocele and gastroschisis and associated malformations. Am J Med Genet A 46A(10): 1280-1285.

5. Forrester MD, Merz RD (2008) Structural birth defects associated with omphalocele and gastroschisis, Hawaii, 1986-2001. Congenit Anom 48(2): 87-91.

6. Benjamin B, Wilson GN (2014) Anomalies associated with gastroschisis and omphalocele: analysis of 2825 cases from the Texas birth defects registry. J Pediatr Surg 49(4): 514-519.

7. Stone P (1999) Gastrointestinal Abnormalities. In: James DK, et al. (Eds). High Risk Pregnancy Management Options, $\left(2^{\text {nd }} e d n\right)$ London: W.B.Saunders, UK Pp. 443-446.

8. Emanuel PG, Garcia GI, Angtuaco TL (1995) Prenatal detection of anterior abdominal wall defects with US. Radiographics 15(3): 517530

9. Raatz SS (2004) Sonographic signs of midgut malformations due to ventral wall defects. J Diagn Med Sonography 20(4): 246-253.

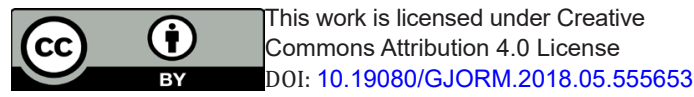

10. Stepan H, Horn LC, Bennek J, Faber R (1999) Congenital hernia of the abdominal wall: a differential diagnosis of fetal abdominal wall defects. Ultrasound Obstet Gynecol 1999 13(3): 207-209.

11. Cyr DR, Mack LA, Schoenecker SA, Patten RM, Shepard TH, et al. (1986) Bowel migration in the normal fetus: US detection. Radiology 161(1): 119-121.

12. Curtis JA, Watson L (1988) Sonographic diagnosis of omphalocele in the first-trimester of fetal gestation. J Ultrasound Med 7: 97-100.

13. Nyberg DA, Fitzsimmons J, Mack LA, et al. (1989) Chromosomal abnormalities in fetuses with omphalocele. Significance of omphalocele contents. J Ultrasound Med 8(6): 299-308.

14. Benacerraf BR, Saltzman DH, Estroff JA, Frigoletto FD (1990) Abnormal karyotype of fetuses with omphalocele: prediction based on omphalocele contents. Obstet Gynecol 75(3): 317-319.

15. Pagliano M, Mossetti M, Ragno P (1990) Echographic diagnosis of omphalocele in the first-trimester of pregnancy. J Clin Ultrasound 18(8): 658-660.

16. Brown DL, Emerson DS, Shulman LP, Carson SA (1989) Sonographic diagnosis of omphalocele during 10th week of gestation. AJR Am J Roentgenol 153(4): 825-826.

17. Gray DL, Martin CM, Crane JP (1989) Differential diagnosis of firsttrimester ventral wall defect. J Ultrasound Med 8(5): 255-258.

18. Gibin C, Touch S, Broth RE, Berghella V (2003) Abdominal wall defects and congenital heart disease. Ultrasound Obstet Gynecol 21(4): 334337.

19. Mayer T, Black R, Matlak ME, Johnson DG (1980) Gastroschisis and omphalocele. An eight-year review. Ann Surg 192(6): 783-787.

20. Reçber D, Özen S (2005) Trizomi 13, Patau Syndrome: A case report. Van Tip Dergisi 12: 29-31.

21. Erk A, Uslu T, Kara F (1999) Prenatal ultrasonographic diagnosis of a thanatophoric dysplasia case. Anatolian J Gynecol Obst 1: 51-53.

22. Sadler TW, Langman J (2012) Third Month to Birth: The Fetus and Placenta. In: Sadler TW (Eds.), Langman's Medical Embryology, $\left(12^{\text {th }}\right.$ edn). Philadelphia, PA. Lippincott Williams \& Wilkins, USA Pp 96-116.

23. Fratelli N, Papageorghiou AT, Bhide A, Sharma A, Okoye B, et al. (2007) Outcome of antenatally diagnosed abdominal wall defects. Ultrasound Obstet Gynecol 30(3): 266-270.

24. Arroyo IC, Pitarch V, García MJ, Barrio AR, Martínez FML (2003) Unusual congenital abdominal wall defects and review. Am J Med Genet A 119(2): 211-213.

25. Gow KW, Bhatia A, Saad DF, Wulkan ML, Heiss KF (2006) Left Side Gastroschisis. Am Surg 72: 637-640.

\section{Your next submission with Juniper Publishers will reach you the below assets}

- Quality Editorial service

- Swift Peer Review

- Reprints availability

- E-prints Service

- Manuscript Podcast for convenient understanding

- Global attainment for your research

- Manuscript accessibility in different formats

( Pdf, E-pub, Full Text, Audio)

- Unceasing customer service

Track the below URL for one-step submission https://juniperpublishers.com/online-submission.php 